\title{
Homeostasis Regulation Pathway
}

National Cancer Institute

\section{Source}

National Cancer Institute. Homeostasis Regulation Pathway. NCI Thesaurus. Code C91822.

An elaboration of the biological or biochemical events that are involved in the maintenance of the internal physiology of an organism. 